\title{
About Taking Criticism
}

\author{
Pamela Oliver \\ Pamela.oliver@wisc.edu
}

This was originally published as a blog post at

https://scatter.wordpress.com/2018/06/07/about-taking-criticism/

\begin{abstract}
This essay is about constructive ways for responding to criticism about how your style as a person of power or privilege may be hurting others in your teaching or advising. Along the way it addresses the broader problems of taking criticism in general and of cultural differences in interaction styles. The punchline is about trying to be who you are (no personality transplants) in a way that respects both yourself and others and helps make your environment feel inclusive for more marginalized people. Sections discuss five issues: (1) Pay attention to issues of power and privilege. (2) Let people know you are open to criticism, including suggestions for classroom strategies. (3) Respect cultural and personal differences in interaction style and look for ways to communicate across these differences with attention to have this interacts with issues of power and privilege. (4) Learn general principles of taking criticism, including staying calm, listening for understanding, asking for time to think and reflect on critiques. (5) Pay attention to the problem of destructive criticism, including destructive relationships and bad classroom dynamics. The conclusion emphasizes that including formerly marginalized groups inevitably produces cultural conflict. Openness to criticism is a way forward for bridging differences in cultural and personal styles.
\end{abstract}

How do you respond when someone criticizes you? What if you think that criticism is unfair or inappropriate? What if you think the critic has a good point and it makes you feel really bad about yourself? This essay is about constructive ways for responding to criticism about how your style as a person of power or privilege may be hurting others in your teaching or advising. Along the way it addresses the broader problems of taking criticism in general and of cultural differences in interaction styles. The punchline is about trying to be who you are (no personality transplants) in a way that respects both yourself and others and helps make your environment feel inclusive for more marginalized people.

Many professors think that it is important for students to be able to take academic criticism as a normal part of learning to be an academic, but are nevertheless outraged at anyone expecting them to take criticism about the way they give criticism to others, if you follow my point. Many people view themselves as pro-feminist pro-minority proqueer liberal social justice advocates and are deeply hurt and offended at being told that their personal style or comments are viewed by others as domineering or racist or sexist or homophobic or classist or patronizing or demeaning. 
Being able to respond calmly and constructively to criticism, whether it is fair or unfair, is an important skill for getting along with other people, for learning new things, and for growing and developing as a human being. It is also an important skill for making positive contributions to your organization's climate and for your ability to communicate across hierarchies and difference.

I believe I have a high level of expertise in the matter of taking criticism because I receive a lot of it. My spouse and children, as much as they love me, will be the first to tell you that they think I can be difficult and annoying at times and have given criticism in hurtful ways. I am blunt and outspoken. My colleagues have often reprimanded me for saying something they felt was inappropriate. I have often been given the feedback that I have talked too much in a meeting or said or did something that offended others.

I am liked a lot more than you might think I deserve to be, and I believe that part of this is due to my adaptive strategy: apologize early and often. I try to make it as easy as possible for people to criticize me, because this is my only chance of getting feedback that will allow me to find out where there may be a disconnect between what I'm intending in my relations with others and what the other person thinks. This is not to say that I agree with all the criticism I have received. I reserve the right of personal integrity and self-judgment and I think about what I have heard. Sometimes I think the criticism arises from a misunderstanding or miscommunication. Sometimes I think the critic is behaving like a total jerk or being completely unreasonable. Sometimes I feel remorse and realize I have been wrong. Sometimes I recognize the validity in the other person's view but keep on doing what I was doing anyway. And lots of times people never tell me when I've hurt them.

So, how can you take criticism constructively, neither over-reacting and feeling destroyed by criticism nor under-reacting and failing to attend to important information about your relationships? How can you open the door to feedback from others so that you can find out what they are thinking and adapt accordingly? In particular, how can you treat criticism of your interaction style as an opportunity to grow without feeling that it means you have to give up who you are as a person?

First, pay attention to power relationships and axes of social privilege. Bosses criticize subordinates but do not expect subordinates to criticize them. Professors criticize students but get upset if students criticize professors. It is my impression that women are used to being criticized, while many men seem to believe that they should never be criticized. White people are often very upset at being criticized by people of color. If you are on the more powerful end of a relationship, you have to assume that the less powerful people will not be candid with you about what they think you do wrong. And if you are getting angry and upset at criticism from a subordinate, you need to ask yourself whether you are just exercising your privilege. (This gets more complicated when we intertwine dimensions of privilege, as female and minority instructors often get criticism from male or white students. More about this later. And, yes, women and people of color as well as white men can engage in destructive criticism campaigns. More about this later, as well.) 
Second, let people know that you are open to criticism. The best way to do this is to say so. I tell people that I am naturally awkward, insensitive and poor at human interaction (which is true); this makes me appear more approachable. After reading a draft of this essay, my daughter told a story about a college friend who was a jerk who was alienating everyone. He realized he had a problem and asked his friends for help. They would tell him when he was being a jerk and, over time, he learned how to stop doing it. (She stressed their feedback was a quick "stop doing that," not extended discourses on how bad he was as a human being.)

I also tell students that I am what some call a "task independent" person. It is not that I am uninterested in your life if you want to tell me about it, but I may not ask, partly because it feels intrusive to ask personal questions and partly because I focus on whatever our "task" is. If our "task" is personal conversation, I can do that, but if our "task" is your master's thesis, I'm probably not going to think to ask about your life. I learned to do this after a diversity training some years ago in which minority students said that impersonality made them feel excluded. Faculty would say: But I'm impersonal to everyone, I don't talk to anybody in the halls. And the minority students, bless them, pushed back and said: It does not matter whether you treat everybody the same. We are not all in the same position. We enter here feeling marginalized, and we need more overt efforts to make us feel welcomed. I have found that this meta-conversation, saying that I'm uncomfortable asking about personal stuff but actually quite willing to talk about it, does help. However, I've also realized as I write this that I should more overtly just ask about personal stuff. How are things going? Are you connecting well in the department? Is your personal life going OK? Are there things in your personal life that are giving you trouble?

One thing you can do in a classroom is explicitly say to students: "It is my goal to make every student in this class feel included and welcome and my goal to help everybody learn this material. I know that we all have different backgrounds and experiences and that I may unintentionally say something that offends you or makes you feel uncomfortable. If this happens, I hope you will tell me." In my classes, this is buttressed by my practice of requiring lecture feedback after every class and telling students that one use of this is to tell me about things that went wrong in the class. My students do tell me when they are offended. If it seems appropriate, I apologize to the class, as I did when I ad libbed an unfortunate rape analogy that upset a lot of people. Other times I report to the class that some students had the concern but don't apologize, as when I report that some students felt my presentation on a topic was biased. Sometimes I have reached out to the individual students who were upset and communicated with them privately. On a few occasions I have allowed students to speak to the class about opinions they felt had not gotten fair treatment in class. I get the daily feedback from students in different ways in different classes, but I find it invaluable both for getting a quick read on how the substance of the class went, and for early warning about student offense or discontent.

Many instructors use anonymous mid-term evaluations as a way of soliciting feedback from students about the class while there is still time to respond to concerns, and generally find that student responses are constructive. (Sample questions: What is going 
well? Are there problems in the class? Are there things happening in class that are hindering your learning?)

Of course, being open to criticism only works if you are actually open, which means that you don't freak out emotionally. No retaliation, no emotional displays, no making the other person feel bad about making you feel bad about what you did or trying to argue them out of their opinion. You listen calmly and thoughtfully and respectfully and promise to think about the issue. If the conversation goes well, you may even be able to have a dialog about the different ways of looking at the thing.

Third, and this is harder than it sounds at first, you need to get to a point of genuinely respecting cultural differences and differences in personal style and really internalize the idea that people can be different from you and still be smart and have something to say worth listening to. People whose style is brash and confrontational, people whose style is timid and self-effacing, people whose style is meandering and indirect all have something to say worth listening to. The problem is not that styles are right or wrong, the problem is negotiating these style differences to find a way to communicate. It is like communicating when you don't speak the same language. If one of you is a monolingual English speaker and the other a monolingual Chinese speaker, can you communicate at all? You may have to speak a pidgin and have a muddled and confusing conversation. What if you are a monolingual English speaker and the person you are talking to is bilingual in Chinese and English but their preferred language is Chinese? Your conversations will be in English because of your handicap-you don't speak Chinese-but if you are an ignorant insensitive imperialistic boor, you will forget the work the other person is doing in conversing in your preferred language and only notice your own work in decoding their accent.

Operating in someone else's culture is similar to operating in a non-preferred language. You can do it, but it takes effort. Culturally aware people try to adapt to the other person's culture, but this itself can be fraught because you may unintentionally insult someone in simplifying your language or in the cultural assumptions you make in trying to adapt. Cultural awareness isn't about being perfect at intercultural communication, it is about having humility and trying to pay attention to interaction cues.

My own style is direct and abrupt. I usually work well with other direct abrupt people. But I have had to learn that not everyone has that style and have learned to adapt and negotiate interaction styles depending on whom I am talking with. This is never seamless, it is hard work, and even when we are making efforts on both sides, it does not always go well. As an aggressive aggressive person myself, I find passive aggression to be particularly infuriating, and I find it stressful to deal with timid people. Nevertheless, if these people are my students or colleagues, it is my job to try to figure out how to work with them so I can teach them or work with them. Sometimes it works, sometimes it does not, but I see it as my job to try.

I have talked to some white men who vocally reject the idea that they should ever have to adapt to somebody else's interaction style. "This is who I am, you just have to put up with it." That statement is an assertion of privilege in a nutshell. It becomes especially obvious when the person becomes angry and offended at being spoken to in the same 
tone and manner as they are speaking to others, especially if those others are women or minorities. They expect deference, they expect to be able to assert the privilege of domination and not having to adapt to others, and they are angry and offended if this is challenged.

The defense of cultural privilege can take more subtle forms among people who see themselves as allies and advocates for women or minorities. In these forms, the privileged person seeks to mentor the disprivileged person into the "proper" way of behaving. Women are told to apologize less and to use male intonation patterns to assert authority. It does not really work, by the way: women who use male intonation patterns are just seen as angry and brash and inappropriate. People who are from cultures or genders with habits of deferential behavior and reticence to assert knowledge publicly are told that they have to change their style to be good academics. They get told that they may as well quit graduate school if they cannot wade their way into a male competitive seminar debate, even as the gender and culture dynamics of the debate prevent them from speaking even when they try. Yes, of course we need to teach students from other cultures what the rules of the dominant academic culture are, but we need to do it in a way that recognizes it as a problem of cultural conflict, not learning the "right" way to behave, and respect the stresses and issues involved in cultural adaptation and learning to be bicultural. Along the way, we can hope that some people will learn that bull elephant battling is not the only way to have an engaged intellectual conversation.

Giving somebody advice about self-presentation is inherently patronizing, and it is important to think through your relationship with them and the complexities of these dynamics. Notice how angry many white men become when we try to give them advice about adjusting their behavior to be less domineering or dismissive of others' feelings. I was once in a mixed-sex committee where I could tell the women were very angry with me. As a woman among women, I was using a self-effacing interaction style to try to mute their anger. (It didn't work; I was ultimately kicked off the committee.) A male professor who is younger than I am told me publicly in the meeting that I should not apologize, that women apologize too much, that we should have a rule that you have to pay 50 cents every time you apologize, and that he trains his students not to apologize. I took offense and said I was not going to pay 50 cents for apologizing. Do you see why his action was so offensive? If not, you need to return to privilege school. He implicitly assumed that his male privilege trumped my age and status privilege. He was patronizing someone who was at least his equal, if not his superior, in status.

If we are going to try to wade through this business of adjusting interaction styles, we have to pay attention to axes of power and privilege. Powerful privileged people have to be persuaded to adapt their behavior and this persuasion is likely to make them feel defensive as their unconscious sense of entitlement is challenged. Weak disprivileged people may want to learn to adapt to the dominant culture, but they may not, and they may feel angry at being told to do so. Some people want to maintain a distinctive cultural or personal identity as part of who they are, and this should be respected, not punished. I have counseled some of my female advisees about being more assertive and self-confident in self-presentation, but I have tried to do it in a way that respected their sense of self and the many different ways to enact womanhood and self-respect. We'd 
discuss other women academics whose style is more soft-spoken than mine as possible templates. You really have to be able to feel comfortable living in your own skin as who you are, while negotiating your relations with others.

In thinking about how to provide constructive criticism to others, we need to consider their backgrounds and experience. People from marginalized communities that are not well represented in the academy have often had a lifetime of experiences of microaggressions and acts of exclusion and may be experiencing the dominant culture of the academy as exclusionary. In this context, remarks that may be meant entirely as supportive and constructive can be experienced as negative. I was once trying to talk a student out of her feelings of inadequacy and imposterism by telling her that I'd been doing this job 30 years and, objectively, she was in the top $10 \%$ of students I had ever worked with and why wouldn't she just believe that I knew what I was talking about. She said, "Don't think you can make my lifetime of experience go away just by talking to me." That was one of the most useful things anyone has said to me. (BTW the person is now a professor at a top institution. I did know what I was talking about.) There is no magic wand to make these larger social contexts go away just because you are trying to be a nice person. If you are privileged, you may get frustrated at having to deal with other people's baggage arising from their oppression, but another way of looking at it is, why shouldn't you have to deal with it? You have benefited from the same system that is making them feel bad.

Fourth, there are some general principles about how to take criticism which apply to this situation as well as others. The Internet is full of self-help on this topic. I point to a few here because so many people seem not to know these basics.

From a Forbes web site by Nicole Lindsey (1) stop your first reaction and stay calm (2) remember the benefit of getting feedback (3) listen for understanding (4) say thank you (5) ask questions to deconstruct the feedback (6) ask for time to process and consider the feedback.

From a Lifehacker blog by Alan Henry: (1) figure out how important the critic is and whether they know what they are talking about (2) analyze the criticism to find the parts that are useful (3) adjust your attitude to avoid getting depressed about criticism or selfcriticism, including getting help from a friend if you are too hard on yourself.

From a Wikihow blog on accepting criticism with grace and appreciation (this one has pictures!) (1) preparatory strategies for learning to be calm and avoid overreaction including exercise, meditation, breathing, self-acceptance; (2) immediate responses, including using humor (I'd be careful with this one), fogging, admitting fault, asking questions, removing yourself from the situation; (3) appreciating criticism, including separating yourself from the criticism, hearing the person out, do better the next time, use the experience to grow.

When we teach classes on race, we have to start the class with some lessons about how to deal with offense. What I tell students in class is, first, no intentional insults, not even as jokes. If somebody says something that offends you, say "I know you did not mean to be offensive, but what you said bothers me because ... " And explain why. If you are the person who has offended someone, you do not have to roll up in a ball and die. You say, 
"Thank you for telling me." You may ask questions to learn more about what the other person thinks. If you are genuinely sorry you may apologize, but do not bother with fake apologies. After you have heard the other person, you may decide to change how you think or talk. Or you may decide that you still think you are right and the other person is wrong, but at least you will have learned that some people will take offense when you say that.

The attitude underlying all these self-help ideas about criticism is a view of people as not dichotomously good or bad, but a self-acceptance of yourself as an imperfect being who can grow and change in response to feedback from others. You do not have to accept every negative thing that is said about you and wallowing in self-hate helps neither you nor anybody else.

Finally, I need to discuss the very real matter of destructive criticism. There are people who dominate others by criticizing them constantly. You know some of these people. Some of them are your colleagues, some are your students. Many of our students or colleagues who seem very timid or fearful have been raised by abusive or hyper-critical people or have been through destructive or abusive relationships. Advisors sometimes create abusive relations with students. As \#metoo has reminded us, this can be sexual, but it can also be non-sexual controlling and hyper-critical relations. Getting out of or recovering from these destructive relationships is difficult and I am not going to pretend to offer solutions, except to say that getting out and avoiding are generally the only good responses. And remember that survivors of destructive relations have often learned to be very attentive to cues that a new person might be problematic and avoid them as a precaution.

For the purposes of this essay, what matters is to recognize these destructive relations exist and pay attention to whether you need to do something about them. Do you have colleagues who really are engaging in destructive criticism with students or young professors? If so, can you work to neutralize them? I believe that we should insist that all students have multiple advisors so that we can have some kind of check on each other. None of us wants to see ourselves as hyper-critical or abusive, but abusers often do not see themselves that way, and the same person may have good relations with many people and abusive relations with only some. It may be worth reflecting on whether you have any habits that could be interpreted as hyper-critical. If students cry after you talk to them or stop talking to you after you have criticized them or you are getting feedback from others that your style is alienating people, maybe you need to look at how your actions might be interpreted by others.

Remember that your students and colleagues bring a lifetime of experience to the table. If you have a student or colleague who seems excessively sensitive to criticism, consider that this sensitivity may arise from prior experience. Criticizing them for their sensitivity is not likely to help. Instead try to consider whether there might be constructive ways to help the student. Can you talk with the student about how they like to receive feedback? If you don't seem to be doing well, can you ask for help from a colleague? Remember also that a lifetime of experiencing racism or sexism or classism or homophobia or antitrans prejudice and attendant microaggressions will make anyone especially sensitive to critique. 
I should also point out that students who have had destructive relations in the past can also respond by engaging in destructive criticism of fellow students or, under some circumstances, faculty. Sometimes the unhealthy climate issues are occurring among students, not just between faculty and students.

Another genre of destructive criticism occurs when students or other subordinates refuse to accept the authority of the professor or leader and make sexist or racist etc. attacks on the person. This is a real thing and many white male faculty do not realize how pervasive this is. There is substantial research evidence that people in disprivileged groups are judged more harshly for exactly the same behavior. And there is a particularly complex dynamic in play when someone in a disprivileged group who is in a position of power has to simultaneously negotiate the need to respect students or subordinates while being subject to power-challenging attacks, many of which take the form of politely-worded statements in class discussions. See this Twitter thread for an example of a polite challenge. Less polite challenges also happen often. The problem of dealing with these dynamics is an extra burden experienced by faculty of color of all genders and, sometimes, white women, especially younger women, as well as people who are visible members of sexual/gender minorities or identities. It adds an extra layer of stress to people's lives that is often invisible to others. I don't know how to make this go away and have no special insight into how to deal with these stresses. But I do want to remind all the faculty from privileged groups who are struggling with challenges from students about their interaction styles that everybody has to face this one way or another, and some are facing it from a position of privilege while others from a position of disprivilege.

We should also acknowledge that there can be a particular kind of destructive problem with group dynamics in teaching situations. I have been a student in, have taught, and have observed many situations in which a group dynamic led a class to turn on an instructor. Usually there was some legitimate initial grievance, but an outspoken ringleader and/ or a group rumoring process led the class to become collectively hostile to the instructor and made it essentially impossible for them to recover the good will of the class no matter what they did. Once the dynamic sets in, the instructor can feel the negative affect of the students and cannot help but react, and the entire situation spirals downward. These are horrible experiences to live through as an instructor. At a minimum it is as bad as having someone crash into you on a bike, sometimes worse. If you are untenured, it can be terrifying because you worry you will lose your job.

Even in these terrible group situations, training yourself to respond calmly and opening to criticism can help. The bad situations are less likely to occur if you have an open channel of communication for students to tell you early if they are aggrieved, because the vast majority of complaining students respond well if their concerns are listened to respectfully, even if you don't do much to respond otherwise. If you said something that got people very angry, a contrite apology early on is much more likely to calm things down than digging in your heels. The second you realize you have a hostile student on your hands and your initial attempts to communicate don't seem to help, I think you should ask for outside help from a chair or colleague or a dean. I have done this myself on several occasions and it helped. 
And if the whole semester has gone bad, it is important to treat it like one giant criticism. Give yourself time to calm down. Try to reflect on what happened and notice whether there were points where you could have responded differently. Are there structural issues that make the class problematic? (e.g. a required class that students are not prepared for) Are there things you can do to affect the structure? Can you talk to people to get more information about what went wrong to look for ways to improve? Can you give yourself permission to let it go and prepare for a better semester the next time?

And for everybody else, when a colleague's class has gone bad, can you respond constructively? Choosing sides and blaming either the instructor or the students is generally not constructive. Instead help look for root causes. Was it a one-time occurrence for a usually good teacher? Are there specific things that can be fixed? Does everybody who teaches this class have problems? Why? Were there race or gender issues in the mix? What can colleagues and community do to help the instructor feel better and do better the next time? What can you do to address students' underlying concerns that fed into the rebellion?

To sum up, we live in a world that is both culturally diverse and hierarchical. There is no reason to expect that the academy is somehow apart from the conflicts of the larger society. There is no way to be inclusive of everyone and avoid conflict. Avoiding conflict through excluding everyone who isn't like the dominant group perpetuates hierarchies. Welcoming formerly marginalized groups into the academy will lead to lots of discomfort and conflict. The way forward is to accept the discomfort and look for ways to form connections and bridges across lines of difference. The only way to do that is to be open to criticism about one's ways of interacting, not because there is something morally wrong about your particular culture or personality, but because naming and talking about the differences and points of conflict and offense are the only way of moving toward working relationships that treat all the participants as full human beings. 